hepatobiliary rickets. Jaundice did not interfere with cutaneous generation of vitamin D. Both patients had developed vitamin $D$ deficiency rickets even though they had been receiving supraphysiological doses of vitamin $\mathrm{D}$ by mouth. Comparison of plasma vitamin $\mathrm{D}$ and 25 hydroxyvitamin $\mathrm{D}$ concentrations indicated no accumulation of vitamin $\mathrm{D}$. Thus there was no evidence that a defect in hepatic 25hydroxylation was responsible for the low 25 hydroxyvitamin $\mathrm{D}$ concentrations.

Most patients with mild malabsorption of vitamin $D$ can be treated with an increase in oral vitamin $D$. Some investigators prefer using 25 hydroxyvitamin $\mathrm{D}$ because it is more polar and slightly better absorbed. If malabsorption is severe and a child develops vitamin $\mathrm{D}$ deficiency while receiving pharmacological doses of vitamin D or 25 hydroxyvitamin $\mathrm{D}$, parenteral vitamin $\mathrm{D}$ or ultraviolet treatment are the next alternatives. The choice depends on the availability of the treatment modality. Intravenous vitamin D formulations are investigational, and their administration is inconvenient.

Although ultraviolet irradiation can be achieved from exposure to sunlight, it is generally available only seasonally, and children with chronic liver disease are often too ill to spend much time outdoors. A sunlamp can be an effective substitute and can be purchased at a modest cost. The effective ultraviolet dose to raise 25 hydroxyvitamin D concentrations varies from lamp to lamp ${ }^{4}$ and depends on skin pigmentation. ${ }^{5}$ The optimal ultraviolet dose can be determined by regular monitoring of 25 hydroxyvitamin $\mathrm{D}$ concentrations.

This paper was prepared with the help of the medical publications department, the Hospital for Sick Children, Toronto.

References

${ }^{1}$ Kobayashi A, Kawai S, Utsunomiya T, Ohbe Y. Bone disease in infants and children with hepatobiliary disease. Arch Dis Child 1974;49:641-6.

${ }^{2}$ Kooh SW, Roberts EA, Theodossiou M, Reilly BJ, Weber JL. Impact of chronic liver disease on bone mineral metabolism in children. Journal of Bone and Mineral Research 1987;2:suppl 1, abstract 95 .

${ }^{3}$ Kooh SW, Jones G, Reilly BJ, Fraser D. Pathogenesis of rickets in chronic hepatobiliary disease in children. $J$ Pediatr 1979;77:51-8.

${ }^{4}$ Devgun MS, Cruickshank AJM, Johnson BE, Paterson CR. Commercially available sun lamps and vitamin $\mathrm{D}$ formation. Postgrad Med J 1981;57:159-63.

${ }^{5}$ Clemens TL, Adams JS, Henderson SL, Holick MF. Increased skin pigment reduces the capacity of skin to synthesize vitamin D3. Lancet 1982;i:74-6.

Correspondence to Dr SW Kooh, The Hospital for Sick Children, 555 University Avenue, Toronto, Ontario, Canada M5G 1X8.

Accepted 3 October 1988

\title{
Are babies more satisfied by casein based formulas?
}

\section{S TAITZ AND E SCHOLEY}

Department of Paediatrics, Children's Hospital, Sheffield

SUMmARY A review of 173 infants who were started on whey based formula showed that $40(23 \%)$ had their feeds changed, usually to a casein based feed by 6 weeks. A double blind randomised trial, comparing casein based with whey based formula confirmed that about $20-25 \%$ of babies have their formula changed within six weeks irrespective of the nature of the feed on which the infant was started.

Two types of infant formulas based on cows' milk are now marketed by baby food manufacturers and are officially approved as infant feeds: those which contain mainly casein as their protein and those which are mainly whey based. ${ }^{1}$ The latter tend to be more highly modified and resemble breast milk more closely in their chemical composition with lower electrolyte and total protein content and a smaller solute load. It is policy in most maternity units to offer babies whey based formulas but many babies are subsequently switched to casein based formulas. $^{2}$

There appears to be a widespread belief among mothers and some health workers that casein based feeds are in some way more 'satisfying' and so a switch to them in crying, unsettled babies or in infants who have various digestive symptoms such as colic, wind, vomiting, or posseting is not unusual. There may even be a notion that switching to a formula perceived as 'stronger' in some ways indicates progress by the baby. It has recently been suggested that parents may be 'voting with their mouths' in switching from whey to casein based formulas and that perhaps maternity units should 'drop their emphasis on whey dominant milks that 
are supposedly nearer to breast milk'. ${ }^{3}$ The review recommends a blind study to ascertain whether there is a genuine difference in satisfaction between casein and whey based formulas.

This study was undertaken to attempt to determine whether there is any basis to the belief that whey based formulas are more likely to be associated with a 'dissatisfied' baby.

\section{Subjects and methods}

This study falls into two parts: a preliminary survey of feeding patterns in normal term infants at their routine, well baby visit at 6 weeks of age, and a prospective, randomised double blind comparison of a whey based formula with two casein based feeds.

\section{PRELIMINARY STUDY}

One hundred and seventy three consecutive mothers attending the well baby clinic at the Jessop Hospital, Sheffield were asked if they had changed their baby's feed and the reason for so doing.

\section{PROSPECTIVE STUDY}

The study was carried out by a research health visitor (ES). Mothers in the ward who had decided to bottle feed their babies were asked within one day of the birth if they would be willing to participate in the trial. They were informed that the three formulas being tested were all standard feeds already freely available on the market. They were offered a free six week supply of feed and were given three weeks' supply initially to take home. A further three weeks' supply was handed over at a scheduled three week home visit. All the babies were seen again at six weeks and at this point the mother was handed a sealed envelope containing the name of the formula they had been feeding the baby.

Three infant formulas were included in the trial: (A) a casein based formula containing maltidextrin as the source of carbohydrate; (B) a casein based formula with lactose as the carbohydrate source; and (C) a whey based formula. The formulas were packed in plain identical containers labelled A, B, and $C$. Their contents were unknown to the research health visitor. Allocation of each child was by computer generated random numbers kept by a departmental secretary in no other way involved with the study. All the feeds were approved, commercially produced, and commonly used. Because of packing problems, formula $B$ was introduced into the random allocation later than $\mathrm{A}$ and $B$, accounting for the smaller number of infants in this group.

At enrolment, data were obtained on social background and child bearing history and the baby underwent measurement of weight, head circumference, subscapular and triceps skinfolds. At three weeks and six weeks' visits questionnaires were filled in and the measurements repeated. Statistical analysis was by $\chi^{2}$, Fisher's exact test, Student's $t$ test, and Mann-Whitney U test.

\section{Results}

\section{PRELIMINARY STUDY}

Of 173 babies $40(23 \%)$ had been changed by 6 weeks of age to a feed other than the (whey based) formula on which they had started. In 30 babies the change was to a casein based formula and in 10 to another whey based feed. In 25 babies changed to a casein based and seven babies changed to another whey based feed there was 'improvement' in the baby. In 29 babies the reason for changing feeds was that the infant was 'not satisfied'.

\section{PROSPECTIVE STUDY}

This report is based on the information gathered at birth and at 6 weeks in all 55 babies included in the random allocation. The gestational age and anthropometric data collected at birth and at 6 weeks are

Table Details of babies studied

\begin{tabular}{|c|c|c|c|}
\hline & \multicolumn{3}{|l|}{ Formula } \\
\hline & $A$ & $B$ & $C$ \\
\hline \multicolumn{4}{|c|}{ Overall outcome } \\
\hline Total No & 21 & 14 & 20 \\
\hline $\begin{array}{l}\text { No }(\%) \text { who } \\
\text { changed feed }\end{array}$ & $5(24)$ & $3(21)$ & $4(20)$ \\
\hline \multicolumn{4}{|c|}{ Body measurements } \\
\hline $\begin{array}{l}\text { Mean }(\mathrm{SE}) \\
\text { birth weight }(\mathrm{g}) \\
\text { Mean }(\mathrm{SE})\end{array}$ & $3460(103)$ & $3430(120)$ & $3420(90)$ \\
\hline $\begin{array}{l}\text { gestational } \\
\text { age (weeks) }\end{array}$ & $39 \cdot 0(0 \cdot 35)$ & $39 \cdot 5(0 \cdot 24)$ & $39 \cdot 6(0 \cdot 27)$ \\
\hline $\begin{array}{l}\text { Mean (SE) } \\
\text { weight at } \\
6 \text { weeks (g) }\end{array}$ & $4780(120)$ & $4510(120)$ & $4730(90)$ \\
\hline $\begin{array}{l}\text { Mean (SE) head } \\
\text { circumference } \\
\text { at } 6 \text { weeks }(\mathrm{cm})\end{array}$ & $38 \cdot 4(0 \cdot 30)$ & $38 \cdot 7(0 \cdot 32)$ & $38 \cdot 3(0 \cdot 21)$ \\
\hline $\begin{array}{l}\text { Mean (SE) } \\
\text { skinfold thickness } \\
\text { at } 6 \text { weeks }(\mathrm{mm})\end{array}$ & $7 \cdot 2(0 \cdot 21)$ & $6 \cdot 6(0 \cdot 41)$ & $7 \cdot 52(0 \cdot 29)$ \\
\hline \multicolumn{4}{|c|}{ Parental assessment of feeds of babies who did not switch } \\
\hline No (\%) with: & $\mathrm{n}=16$ & $\mathrm{n}=11$ & $\mathrm{n}=16$ \\
\hline Contented baby & $16(100)$ & $8(72)$ & $15(94)$ \\
\hline Satisfied baby & $15(94)$ & $7(64)$ & $14(88)$ \\
\hline $\begin{array}{l}\text { Baby who had } \\
\text { digestive } \\
\text { symptoms }\end{array}$ & $6(37)$ & $3(27)$ & $5(32)$ \\
\hline
\end{tabular}


summarised in the table. There were no significant differences between the three groups.

The overall outcome and parental assessment of the infants is also summarised in the table. There was no significant difference between the three milks as regards changes of formula. The apparently increased rate of dissatisfaction with formula $B$ and reduced incidence of gastrointestinal symptoms was not significant.

\section{Discussion}

Whey protein accounts for $70 \%$ of the protein in human milk, whereas in cows' milk it accounts for only about $20 \%$, the remainder being caseinogen. Some infant formulas (casein based) are made from non-adapted cows' milk while in others (whey based) the milk is adapted to have a protein composition closer to human milk. As whey protein contains a higher proportion of essential amino acids, lower total protein contents are possible. Whey based formulas have a lower solute load than casein based but both types of milk are considered satisfactory infant feeds. One study has, however, found better weight gain in infants fed whey based feeds. ${ }^{4}$ The differences were small and the significance of the findings for infants are not clear.

In the present study no significant differences were noted in rates of weight gain in infants fed casein or whey based feeds. In both groups of infants, however, there was a tendency for between one fifth and a quarter of babies to undergo a switch in feeds. The proportion of those switching was similar in the three allocation groups and the preliminary study where the initial formula (whey based) was different from that used in the prospective study. Furthermore, this proportion is similar to that in the survey by the Office of Population Censuses and Surveys on infant feeding for 1985. Data from the United States indicates that a similar proportion of bottle fed babies have their formula changed, usually to a soya based feed. ${ }^{5}$ Whereas in Britain lack of satisfaction is the reason usually given for changing, in the United States it is usually ascribed to 'cows' milk allergy'. The difference is probably explained by the fact that the babies in the American study came mainly from middle class families whereas those in the present study were from a lower socioeconomic group. The American mothers were probably more aware of the possibility of 'allergy' as an explanation for their babies' symptoms (usually excessive crying) ascribed to 'lack of satisfaction' by the British mothers. It is interesting that about as many mothers in the American study who changed their babies to soya expressed approval of the change as British mothers whose babies were switched to either casein or whey based milk feeds. These findings indicate that there are a variety of reasons, unrelated to the nature of the feed but wrongly ascribed to the contents of the bottle, which lead to formula switching with a built in tendency for a proportion of mothers to do so. Paediatricians have long advised against speculative changes of formula for many good reasons. ${ }^{6}$ The findings of this paper should add to their resolve.

We wish to thank the nursing staff at the Jessop Hospital for their collaboration and Milupa for providing the grant which enabled this study to be carried out.

\section{References}

${ }^{1}$ Raiha NCR. Nutritional proteins in milk and the protein requirements of normal infants. Pediatrics 1985;75(suppl): 136-41.

${ }^{2}$ Martin J, White A. Infant feeding 1985. London: HMSO, 1988. (Office of Population Censuses and Surveys.)

3 Anonymous. Present day practice in infant feeding. Lancet 1988;i:975-6.

4 Gunn TR, Stunzner D. A comparative trial of casein or wheypredominant formulae in healthy infants. NZ Med J 1986;99: 843-6.

5 Forsyth BWC, McCarthy PL. Problems of early infancy, formula changes, and mothers beliefs about their families. J Pediatr 1985;106:1012-7.

6 Taitz LS. Soy feeding in infancy. Arch Dis Child 1982;57:814-5.

Correspondence to Dr LS Taitz, Department of Paediatrics, Children's Hospital, Sheffield S10 2 TH.

Accepted 3 October 1988 